\title{
DISTINGUISHING BELIEF AND IMAGINATION
}

BY

NEIL SINHABABU

\begin{abstract}
Some philosophers (including Urmson, Humberstone, Shah, and Velleman) hold that believing that $\mathrm{p}$ distinctively involves applying a norm according to which the truth of $\mathrm{p}$ is a criterion for the success or correctness of the attitude. On this view, imagining and assuming differ from believing in that no such norm is applied. I argue against this view with counterexamples showing that applying the norm of truth is neither necessary nor sufficient for distinguishing believing from imagining and assuming. Then I argue that the different functional properties of these mental states are enough to distinguish them, and that norm-application doesn't help us draw the functional distinctions.
\end{abstract}

Believing that $\mathrm{p}$, imagining that $\mathrm{p}$, and assuming that $\mathrm{p}$ are ways of representing that $\mathrm{p}$. What distinguishes believing from imagining and assuming? On one view, for a representation to be a belief requires that it be the object of another attitude which applies a norm of truth to it. Imagining and assuming differ from believing in that these representations aren't the object of any further attitude applying a norm of truth to them. We could call this the further-attitude truth-norm-application theory of belief (I'll call it the 'norm-application theory' for brevity). John Urmson, Lloyd Humberstone, Nishi Shah, and David Velleman defend versions of the norm-application theory.

It is not hard to see why some philosophers are attracted to the normapplication theory. It's widely agreed that truth is the norm of belief. Also, most people have attitudes according to which true beliefs are better than false ones. Neither of these things hold for imagining or assuming. So it seems attractive to use this distinction between the norms we apply to distinguish believing from imagining and assuming. I agree that truth is the norm of belief, that most people have attitudes favoring true belief, and that imagining and assuming differ in these normative and

Pacific Philosophical Quarterly 94 (2013) 152-165DOI: 10.1111/j.1468-0114.2012.01449.x (C) 2012 The Author

Pacific Philosophical Quarterly (C) 2012 University of Southern California and Blackwell Publishing Ltd. 
psychological respects. Still, I reject the norm-application theory. ${ }^{1}$ I'll argue that it would lead us to draw the line between belief and the other attitudes incorrectly, and that a better option is available.

I'll begin by examining the views of norm-application theorists in more detail. Then I'll present counterexamples both to the sufficiency and the necessity of applying a norm of truth for distinguishing between believing and imagining. These counterexamples extend naturally to the distinction between believing and assuming. I'll argue that the different functional properties of belief and imagining are enough to distinguish these states, making the norm-application theory unnecessary.

\section{The norm-application theory}

In 'Memory and Imagining,' Urmson asks how we can distinguish remembering a past event from imagining it. ${ }^{2} \mathrm{He}$ rejects Hume's view that the difference ultimately comes down to the greater vivacity of memory, and also points out that the fact of the event's having happened is not sufficient to make the mental state one of belief. He offers the striking claim that we can distinguish believing that $\mathrm{p}$ and imagining that $\mathrm{p}$ without considering the attitude towards $p$ itself. For a mental state to be a memory rather than an imagining, it is sufficient for the agent to have the right intention concerning it:

We do not have to look for any special features of our mental pictures or of the tale we tell, nor need we ascertain their relationship to reality or to anything else. All we have to do is to know what criteria of success are applicable, and that is a question which depends upon our own intentions. We are recollecting not if we did conduct the defence in the trial but if it matters whether we did. We are imagining if some such criteria of success as general verisimilitude, or interestingness are the relevant ones (pp. 87-88).

As he says later, the difference between memory and imagination is 'whether we have or have not chosen to act so that resemblance to actuality is a criterion of the success of our activity' (p. 90). This attitude of choosing - as he presents it above, an intention - is what makes the difference between memory and imagination. In what follows, I'll generalize on Urmson's view, treating it as if he applied it not only to mental states concerning the past, but also to belief and imagination in general.

Humberstone approvingly cites Urmson in presenting an account of what it means for beliefs to have their characteristic direction of fit. ${ }^{3}$ While Humberstone's interest is in distinguishing belief from desire, he offers the similar view that 'unless the attitude-holder has what we might call a controlling background intention that his or her attitudinizing is successful only if its propositional content is true, then the attitude taken is not 
that of belief' (p. 73). While Humberstone takes no position on whether having such an intention is sufficient for belief, he thinks it's necessary: 'unless one takes there to be a criterion of success in the case of an attitude towards the proposition that $\mathrm{p}$, and, further, takes that criterion to be truth, then whatever else it may be, the attitude in question is not that of belief' (p. 73). He seems to regard this as a conceptual truth: 'unless one counts one's (current) intentions in $\varphi$-ing that $p$ as thwarted if it is not true that $p$, one's $\varphi$-ing that $p$ does not constitute believing that $p$. Thus the very concept of belief imports its own criterion of success' (p. 73).

Like Humberstone, Shah and Velleman hold that the concept of belief has a normative component which plays some role in distinguishing believing from imagining and assuming. They accept that the non-normative component of the concept of belief will do a lot of this work. However, they think there are some "cases in which the question whether a truth-regulated acceptance should be classified as a belief appears to be underdetermined by the facts' (p. 510). ${ }^{4}$ In these cases, whether we classify the truth-regulated acceptance as believing or as imagining or assuming will be determined by whether we apply the norm of truth to it. In an earlier paper, Shah argues that this norm applies to belief alone: "truth functions as a standard of correctness only for belief and only evidence of truth provides a reason for belief' (p. 471). ${ }^{5}$ In their joint paper they answer the question, 'What distinguishes belief from the other modes of acceptance?' by saying that 'conceiving of an attitude as a belief, rather than an assumption or an instance of imagining, entails conceiving of it as an acceptance that is regulated for truth, while also applying to it the standard of being correct if and only if it is true' (p. 497). Applying this standard to an acceptance that $\mathrm{p}$, on their view, 'consists in accepting the norm of truth for that acceptance, where accepting a norm is a conative attitude that, among other things, disposes one to follow the norm and inhibits one from following any alternative' (p. 510). So to regard an acceptance that $\mathrm{p}$ as a belief, one must have a conative attitude of norm-acceptance towards it. This noncognitive attitude of norm-acceptance seems to follow the view of Allan Gibbard. ${ }^{6}$

Shah and Velleman's view ends up being like those of Urmson and Humberstone in treating beliefs as representations to which the believer has a further truth-favoring attitude, though their route to this position is more complex. Strictly speaking, they merely require the norm of truth to be applied by the belief-attributor, not the believer. But they ground belief-attribution in the believer's mind by appealing to 'a social norm of deferring to the subject as to whether he believes that $p$, is imagining that $\mathrm{p}$, or is treating $\mathrm{p}$ as a working hypothesis' arising from 'respect for his rational agency' (p. 515). Where this norm of deference is upheld, beliefattributors will apply the same norms that subjects of belief-attribution do. This makes it appropriate to call representations beliefs only if the subject applies a norm of truth to them. From now on I'll assume that this norm 
of deference usually holds. This makes Shah and Velleman's view similar to those of Urmson and Humberstone, requiring believers themselves to have a further truth-favoring attitude towards their representations. Charity recommends this interpretation. If the norm of deference didn't usually bring others' belief-attributions in line with the subject's, whether to regard someone else as a believer or as an imaginer would often be settled by our own normative judgments rather than by empirical evidence about the person. This would be a strange way to attribute beliefs.

While all these views agree that belief is necessarily accompanied by the application of a norm according to which truth is its criterion of success, they differ on (at least) 3 issues: which mental state constitutes applying a norm, whether it's a conceptual truth that a norm of truth must be applied, and whether the application of this norm is sufficient for making a representation that $\mathrm{p}$ into a belief. On the issue of which mental states are involved, Urmson and Humberstone understand applying a norm of truth as having an intention that beliefs be true, while Shah and Velleman understand it as having a norm-acceptance of truth. On the question of modal status, Humberstone, Shah, and Velleman each regard their version of the norm-application theory as a conceptual truth. Urmson is silent on this point, perhaps because the distinction between conceptual truth and mere metaphysical necessity was less salient when he was writing. On the question of necessity and/or sufficiency, Urmson alone is explicitly committed to both the necessity and the sufficiency of the application of the norm for distinguishing believing from imagining. Humberstone commits himself only to necessity. Shah and Velleman deny sufficiency in invoking a non-normative component of the concept, but allow that the application of a norm will tip the balance in some cases. They also embrace necessity.

I'll argue against norm-application theories involving any permutation of these positions. Whether applying a norm of truth consists in intending to believe the true or accepting a norm of only believing the true, whether the modality involved is conceptual or merely metaphysical, and whether it's necessary, sufficient, or both, it won't help us distinguish believing that $\mathrm{p}$ from the other ways of representing that $\mathrm{p}$. Applying a norm of truth is neither necessary nor sufficient for belief even as a psychological matter. Counterexamples to the sufficiency of norm-application for turning imagination into belief will come next, and counterexamples to necessity will follow.

\section{Counterexamples to sufficiency}

Norm-application theories don't give correct sufficient conditions for one's representation that $\mathrm{p}$ being a belief rather than an imagining. Applying a 
norm of truth to a representation that would otherwise be an imagining doesn't make it a belief.

I can apply a norm according to which it's permissible to represent that someone loves me only if it's true that she loves me. Perhaps I've decided that it's unjust to imagine that others love me when in fact they don't. Or perhaps I saw others who thought that way passionately express their view, and unthinkingly came to apply the norm to my own imaginings. Either way, my imagining won't become believing even if this norm applies to my imaginings and I successfully regulate them for truth. Of course, because of Moore's paradox, I'll also have to believe that she loves me if I'm to imagine that she loves me and successfully follow this norm. But my mental state of imagining that she loves me is still distinct from my mental state of believing. I'll believe that someone loves me, and additionally imagine that she loves me. Applying the norm to my imagining won't turn it into an additional belief, or collapse it into the other belief. Imagining what I know to be true, after all, isn't problematic. While away at a conference, I can imagine returning to the office, as I know I will. I can imagine the departmental events that I know are going on and that have gone on in my absence. In all of these cases, I both imagine and believe. In cases where my norm of truth extends beyond belief to representations like imagining, the norm-application theorist's sufficient conditions will collapse these distinct and simultaneous mental states into believing alone.

The most powerful counterexamples to sufficiency arise when I apply a norm but violate it. Suppose I apply the norm of not representing that someone loves me unless it's true that she does. Suppose that I believe she doesn't love me. And suppose that despite myself, I get carried away with my fantasies and vividly imagine that she loves me, failing to live up to my own norm. (Any plausible norm-application theory will allow our mental processes to fail to live up to the norms we apply to them. One can have intentions or norm-acceptances ruling out wishful thinking and still be afflicted by it.) If applying a norm of truth is sufficient for turning imagination into belief, it'll turn out that when I represent her as loving me, I believe that she loves me. But this is deeply implausible. Runaway fantasies that contravene my norm of representing only the true don't turn into beliefs just because I've applied the norm.

Norm-application theorists might think to protect themselves from this second counterexample by modifying their view so that successfully following one's norm of truth, rather than merely applying the norm, is sufficient for making one's representation a belief. Successful following shouldn't involve actively thinking about the norm itself, as that would make the condition far too strong to be useful. It should merely involve believing in accordance with the norm. This strategy faces three problems. First, and most straightforwardly, it doesn't deal with the earlier counterexample 
where I faithfully follow my norms in imagining the true, and yet have a mental state of imagining that is distinct from believing.

The second problem, which arises only if successful following is made a necessary condition as well as a sufficient condition, is that the normapplication theory will no longer treat false beliefs as beliefs. All the norm-application theorists I've discussed claim that truth itself is the norm of belief. If one's belief is false, one is unsuccessful in following the norm. So making it necessary that I successfully follow the norms of truth to have a belief will make all false beliefs into counterexamples to the normapplication theory.

Third, a norm-application theorist who adopts this strategy must beware sliding out of the norm-application theory. What does one add to a norm-application theory when one changes the sufficient conditions for belief from a norm being applied to some representation, to that norm being successfully followed? One simply adds conditions concerning what the representation itself does. Depending on the content of the norm, these can be conditions under which the representation arises, persists, and vanishes, or ways that it interacts with other mental states. The normapplication theorist's opponent holds that properties of belief apart from the norm's application to it are necessary and sufficient for belief, so that the application of a norm does no work in distinguishing beliefs from other mental states. In building in the condition of successful following, the norm-application theorist incorporates key elements of an opposing account. If these elements as opposed to the application of the norm itself are what really do the work of explaining why some representations are beliefs and others aren't, we don't need the norm-application theory.

\section{Counterexamples to necessity}

Norm-application theories don't give correct necessary conditions for a representation that $\mathrm{p}$ being a belief rather than an imagining. One can believe that $\mathrm{p}$ even if one doesn't apply a norm of truth to one's attitude.

Consider Priscilla, a committed pragmatist who is thoroughly convinced that truth has no normative significance with respect to believing that $\mathrm{p}$ or any other representations that $\mathrm{p}$. The only norms she applies to her representations are norms of utility-maximization. She holds that she ought to only have those representations that maximize utility, whether or not they match up with reality. It's a bad and presumably unintended consequence of all the norm-application theories covered here that her wholehearted pragmatism makes it impossible for her to have beliefs. Since she doesn't apply norms favoring truth for any of her representations, and applying a norm is necessary for belief, none of her representations are beliefs. This is wildly counterintuitive. While pragmatism may be an 
implausible view about epistemic norms, wholeheartedly accepting it doesn't destroy one's ability to have beliefs.

Or suppose a sensationalistic popular science article has convinced Oliver that positive thinking reduces his risk of cancer. Worried about his health, he abandons the norm of truth and comes to apply a norm of optimism to all his believings and imaginings. ${ }^{7}$ Depending on one's preferred view about norm application, he can either intend to mentally represent good things or accept a norm of representing good things instead of a norm of truth. If the norm-application theory gave correct necessary conditions for belief, Oliver's abandonment of the norm of truth would eliminate all of his beliefs, turning them into another kind of representation. But clearly his beliefs persist even as he clings to his ill-chosen norm.

The best response I can advance on behalf of norm-application theorists is that Priscilla and Oliver can't really abandon the norm of truth. While they profess deviant norms, they remain implicitly committed to the norm of truth, and that's why they're still believers. What evidence could the norm-application theorist cite to support the claim that Priscilla and Oliver are mistaken about whether they still accept the norm of truth? Perhaps the evidence is that they don't end up with radically different processes of belief-formation. When faced with powerful and depressing evidence, Priscilla and Oliver will still form pessimistic beliefs that might make their lives worse by saddening them. Thus they contravene their professed pragmatic and optimistic norms while following the norm of truth that they claim to reject. Norm-application theorists might take this as evidence that Priscilla and Oliver really still accept the norm of truth, and thus explain our intuition that they're still believers.

Using our doxastic processes as evidence for the norms we accept in this strong a fashion involves attributing a great deal of control to our norms - a dangerous commitment for a norm-application theorist. If doxastic processes that follow the norm of truth override one's avowal of pragmatic or optimistic norms, demonstrating that truth is really one's norm, can wishful thinking or logical fallacies override one's profession of the norm of truth, demonstrating that one really holds deviant norms permitting these doxastic processes? Norm-application theorists shouldn't take the actual nature of our doxastic processes as a sign of the norms we accept, because this leaves them with nothing good to say in the cases where our doxastic processes go awry. In the end, much of why our doxastic processes operate the way they do will come down to internal descriptive features of belief itself, and not the way that norm-application affects it.

Since people can believe even if they don't apply a norm of truth, the norm-application theory gives incorrect necessary conditions for belief. This is a problem for all the norm-application theorists I've cited, as they all endorse a necessity claim. 


\section{Assuming}

Now I'll consider how to distinguish believing from assuming. Shah and Velleman claim that their view helpfully distinguishes these states. I'll argue that the norm-application theory fails here, just as it fails with the distinction between believing and imagining, and offer a counterproposal on which assuming is a kind of imagining.

'Assuming' is ambiguous between two different mental states. Sometimes assuming that $\mathrm{p}$ is just a way of believing that $\mathrm{p}$ - for example, when I assume that my plane will arrive on time and make travel plans on that basis. This kind of assuming isn't interesting for our purposes. The interesting kind of assuming, and the one Shah and Velleman discuss, is the kind where we consider a position that we don't believe in order to see how it could be defended or what follows from it. Shah's earlier paper discusses 'the bizarre but intriguing axiom that you assume in order to trace its implications' (p. 471). This is the kind of assuming worth considering for the purpose of the debate, and the kind I'll deal with.

Norm-application theories don't give good sufficient conditions for distinguishing believing and assuming. As in the second counterexample to sufficiency for distinguishing believing and imagining, let's consider what happens when someone accepts truth as the norm of correctness for assuming, but still ends up assuming what she knows to be false. Suppose Vera decides to make a great sacrifice for the sake of truth: she'll no longer even assume the false. She applies a norm of truth even to her assumptions. But one day as she tries to construct a reductio ad absurdum argument against a position she rejects, she gets carried away and briefly assumes that it's true, violating the norm. Obviously, this doesn't mean that she briefly believed the position she rejects. To assume the false, violating one's norm of truth for assuming, isn't to believe the false. In retrospect, the only flaw Vera would attribute to herself is that of violating her own norms for assuming. She'd be right to deny that the norm of truth turns her assuming into believing, and results in her having a false belief. This case shows that applying a norm of truth to an act of assuming is insufficient to turn it into a belief.

For counterexamples to necessity, we can return to the cases of Priscilla and Oliver from the previous section. Does abandoning the norm of truth and instead applying pragmatic or optimistic norms turn all their believings into assumings? If it does in any way, it's only in the uninteresting sense described before, where I assume that my plane will arrive on time in making travel plans. It definitely doesn't turn their believings into assumings of the kind that the norm-application theorist wants to distinguish, like the axiom that you assume to determine its implications. 
Here I'll briefly suggest an alternative account of assuming. Assuming of the kind we're discussing seems to be a way of imagining that $\mathrm{p}$. It differs from other acts of imagining simply in its purpose, which typically is something like determining what follows from $\mathrm{p}$, how $\mathrm{p}$ can be defended, or how to plan for $\mathrm{p}$. When one assumes that some bizarre but intriguing axiom is true, one imagines that it holds and one further develops the imagined scenario to determine what else would be true. ${ }^{8}$ When one assumes that one's erratic chess opponent will make the best available moves, even though one may believe that she'll in fact play otherwise, one imagines one's opponent making these moves and then further develops the imagined scenario to include the way that both players will proceed. If this is the right way to understand assuming, and if we already have a distinction between believing and imagining to draw on, we won't need the normapplication theory to distinguish believing from assuming. Instead of pointing to how a norm of truth applies to believing but not to assuming, we can note that assuming is a kind of imagining, while believing is not.

\section{Functional properties distinguish belief and imagination}

If the application of a norm isn't what distinguishes believing from imagining, what does? The functional properties of belief provide the answer. Belief's functional properties differ significantly from the functional properties of imagination, distinguishing the states. ${ }^{9}$ The important and difficult task of precisely characterizing the differences between imagination and belief is beyond the scope of this article. I'll merely indicate some ways in which they can be distinguished. My goal is to show that the distinction can be drawn without assistance from the norm-application theory.

What are the functional properties of belief? Here are four properties that have been plausibly suggested as essential to a mental state's being a belief. First, beliefs stand in particular inferential relations to one another - if one believes that $\mathrm{p}$ and believes that if $\mathrm{p}$ then $\mathrm{q}$, and reflects on these propositions, one typically forms the belief that q. Second, when perceiving that $\mathrm{p}$ and directing one's attention towards this feature of the perceived state of affairs, one typically forms the belief that $\mathrm{p}$. Third, if one desires that $\mathrm{d}$ and believes that action a would make $\mathrm{d}$ more likely, this will give one some motivation to a. Fourth, if one believes that $\mathrm{p}$ and believes that one is in conditions favoring sincere expression of that belief, one will assert $\mathrm{p}^{10}$

The first property - the capacity for particular sorts of inferential relations - is the one that comes closest to being shared by both belief and imagination. If I believe that my house is on fire, and believe that if my house is on fire I'm in danger, I'll believe that I'm in danger. Similarly, if I imagine that my house is on fire, and imagine that if my house is on fire 
I' $m$ in danger, I'll be imagining that I'm in danger. But even here, there's material that helps us construct a distinction between believing and imagining. Suppose I imagine that my house is on fire and that I'm an indestructible superhero who isn't endangered by fire. At the same time, I believe that my house isn't on fire and that I'm an ordinary mortal who is endangered by fire. In this state, I have representations which include both the premises from which I could conclude that I'm in danger. But since one premise is represented in belief and the other is represented in imagination, I don't draw the conclusion that I'm in danger, either in belief or within the imagined scenario. While we might not be able to tell which mental states are beliefs and which are imaginings based on their inferential properties, their inferential properties differ in that they primarily produce states of their kind, and not the other. A very simple illustration of this phenomenon comes when we believe $p$ and imagine $\neg$ p. This set of mental states isn't psychologically unstable in the way that believing contradictions or imagining contradictions is.

The second property - the way that perceptual states shape belief - is one that imagination clearly doesn't share. As I read Macbeth, my sensory perceptions are of the words in the open book before me. I believe that I'm reading a book and that particular words are on the page. I imagine three witches chanting over their cauldron. I don't believe that there are or ever were witches. Yet I vividly imagine that they exist and that they chant with a hypnotic rhyme. Imagining departs from perceptual evidence more drastically than belief can.

The third property - the relation to motivation - also marks a clear difference between imagining and believing. If imagination and belief had the same motivational properties, imaginative people would be constantly engaging in utterly bizarre behavior, reshaping their entire lives to fit spur-of-the-moment daydreams. Velleman has argued that the motivational differences between imagining and believing aren't so stark, and that the way we act when we engage in make-believe demonstrates that imagination has a motivational component as well. ${ }^{11}$ But as has been widely - and in my view, decisively - argued in response to Velleman, the purported motivational role of imagination in cases of make-believe is merely an instance of the motivational role of belief. In these cases, one's imaginings connect to one's beliefs in a way that produces means-end beliefs appropriate for motivating action. ${ }^{12}$

The fourth property - that we sincerely assert what we believe, under favorable conditions for sincere assertion - also marks a difference between belief and imagination. If I'm at a party with a platonic friend, and someone asks whether we're dating, this may spur me to briefly imagine the non-actual situation in which we're dating. Whatever my feelings about the imagined situation may be, I'll respond in the negative. Belief, not imagination, determines what I assert. Perhaps there's some 
type of speech-act - supposition or storytelling - in which I state my imaginings and not my beliefs. But that there is such a distinction between speech-acts demonstrates the difference between believing and imagining.

\section{Functional properties aren't grounded in the norm-application theory}

How might norm-application theorists respond to these differences between the functional properties of believing and imagining? They must answer the objection that since believing and imagining already differ in these functional respects, there's no need for the norm-application theory. The best response would be to argue that these functional differences are grounded in our application of the norm of truth to believing but not to imagining. We can see how this response would work with respect to the fourth property, that belief is distinguished by its aptness for sincere assertion. If the difference between assertion and supposition is merely that speakers apply the norm of truth to assertions and not to suppositions, the norm-application theory will successfully explain this property of believing. But attitudes in which one applies a norm of truth can't explain the other three properties, and even if norms of truth themselves explain the functional properties of belief, further attitudes of accepting the norm of truth don't play any interesting explanatory role.

First, applying a norm of truth couldn't explain why beliefs interact inferentially with beliefs and not with imaginings. The norm-application theorist can't plausibly argue that mental states to which the truth norm is applied only interact inferentially with others to which the truth norm is applied. Segregating inferential relations this way would leave no room for practical inference, in which beliefs interact with desires, which are exempt from a norm of truth, to produce intentions and actions. So trying to explain why belief doesn't interact so directly with imagination by claiming that there are direct inferential connections between states only if we apply the same norms to them will fail.

Second, it's hard to see how applying a norm of truth could explain the responsiveness of belief but not imagination to perceptual states. As demonstrated in the earlier counterexamples to the sufficiency of applying a norm of truth for turning imagination into belief, applying this norm won't make imagination respond to perceptual states in the way belief does. Runaway fantasies unmoored from our perceptual states remain possible. Even more clearly, withholding the application of the norm won't make belief nonresponsive to perceptual states in the way imagination is. The pragmatist forms perceptual beliefs just like anyone else.

Third, it doesn't seem that applying the norm of truth explains the motivational efficacy of means-end beliefs and the motivational inefficacy 
of means-end imaginings. To reject the necessity of applying the norm for motivational efficacy, we can note that a pragmatist who rejects the norm of truth for belief can still act on a belief-desire pair. And to reject the sufficiency of applying the norm for motivational efficacy, we can see that applying the norm to imagining wouldn't lead one to act on one's imagining. One might still act on the means-end belief that underwrote the permissibility of the means-end imagining, but the belief and the imagining would be distinct mental states. One would be a plausible premise for practical inference while the other wouldn't.

One might suggest another way to explain the functional differences between believing and imagining in terms of norms. ${ }^{13}$ Perhaps the functional properties of belief are picked out by the norms governing belief. Epistemic norms require beliefs to interact with each other and with perceptual states in particular ways. Practical norms require particular relations between belief, desire, and action. Norms of assertion require particular relations between beliefs and assertions. In each case, what the norms require closely tracks the functional properties. Given the close fit between the norms and functional properties of belief, perhaps the latter are in some way grounded in the former. This view would fit a construal of the 'function' in 'functionalism' as a normative term. ${ }^{14}$

Even if the norms of belief explain what its functional properties are, this doesn't support the distinctive claim of the norm-application theories criticized here - that a further attitude of accepting the norm of truth for some representations is necessary or sufficient for making those representations beliefs. As the counterexamples to necessity presented earlier suggest, it's possible for representations to be beliefs even if one lacks such a further attitude. We might criticize pragmatists and others who reject the truth norm for applying the wrong norms to their beliefs. In doing so, we would treat their mental states as beliefs, subject to the norm of truth, even though they don't apply this norm themselves. This shows that epistemic norms can do the work of making particular criticisms appropriate even if the criticized agents reject the epistemic norms. And if epistemic norms can do this kind of work without being accepted, why can't they do the further work of explaining what belief's functional properties are without being accepted? Even if a functional characterization of belief depends in some way on the norms of belief, it doesn't depend on a further attitude of norm-application in the way that the norm-application theories considered here suggest.

\section{The moral of the story}

I'll conclude by noting the significance of this issue for a question at the nexus of normative theory and philosophical psychology. Is 
norm-application psychologically more fundamental than belief? The norm-application theory claims that the answer is yes. Its defeat suggests that the answer is no.

The norm-application theory claims that the human capacity to apply norms is an utterly fundamental fact about our psychology, deeper even than the capacity to have beliefs. Belief, on a strong version of the normapplication theory, is reducible to generic representation plus the application of a norm of truth. So rather than treating belief as a primitive psychological term, we should treat norm-application as primitive (or move as far in this direction as the norm-application theory is strong). Norm-application then looks to be one of the fundamental building blocks of our propositional attitudes. I've argued that this picture doesn't help us distinguish believing from imagining. While it's significant that we apply norms, we shouldn't restructure our understanding of mental states as basic as belief around this fact.

\section{Department of Philosophy \\ National University of Singapore}

\section{NOTES}

1 If application of a truth norm doesn't explain why belief is subject to a norm of truth, what does? I'd suggest that truth is the norm of belief not because of any mental state we have toward belief, but as a mind-independent normative fact. This is the standard way to understand moral norms. What it's right to do depends on objective moral facts, not on what we judge to be right.

2 Urmson, J. (1967). 'Memory and Imagination,' Mind 76(301), pp. 83-91.

3 Humberstone, I. L. (1992). 'Direction of Fit,' Mind 101(401), pp. 59-83.

4 Shah, N. and Velleman, D. (2005). 'Doxastic Deliberation,' Philosophical Review 114(4), pp. 497-534.

5 Shah, N. (2003). 'How Truth Governs Belief,' Philosophical Review 112(4), pp. 447-482.

6 Gibbard, A. (1990). Wise Choices, Apt Feelings. Cambridge, MA: Harvard University Press.

7 Shah and Velleman suggest that pragmatic considerations are appropriate for determining whether to apply a norm of truth. They write: 'The question whether to apply the concept [of belief] appears to hang on pragmatic considerations of the sort that would determine whether to apply a noncognitive norm' (p. 514).

8 How, then, should we make sense of assuming a contradiction in order to see whether everything follows from it? Does one actually have to imagine the contradictory state of affairs that the contradiction describes? I think one usually just imagines the contradictory sentence having the property of truth, without unpacking this to imagine the described state of affairs. This sort of imagining permits the syntactic operations involved in logical deduction.

9 For empirically informed work on this issue, see Nichols, S. (2006). 'Just the Imagination: Why Imagining Doesn't Behave Like Believing,' Mind \& Language 21, pp. 459-474, and Gendler, T. (2006). 'On the Relation Between Pretense and Belief,' in M. Kieran and D. M. Lopes (eds) Imagination, Philosophy, and the Arts. New York: Routledge, pp. 125-141. These 
authors don't address the norm-application theory, but the differences between believing and imagining which they describe suggest functional differences that would allow the distinction to be drawn without help from the norm-application theory.

${ }^{10}$ These are drawn from Schwitzgebel, E. (2006). 'Belief,' in E. Zalta (ed.) Stanford Encyclopedia of Philosophy, available at http://plato.stanford.edu/entries/belief. The fourth condition seems to be reducible to the third, since assertions are actions, but I won't address this here.

${ }^{11}$ Velleman, D. (2000). 'On the Aim of Belief' in his The Possibility of Practical Reason. Oxford: Oxford University Press.

${ }^{12}$ See O'Brien, L. (2005). 'Imagination and the Motivational View of Belief,' Analysis 65(1), pp. 55-62, for a straightforward response of this sort. Similar comments along these lines appear in Noordhof, P. (2001). 'Believe What You Want,' Proceedings of the Aristotelian Society 101, pp. 247-265. The view in Van Leeuwen, D. S. (2009). 'The Motivational Role of Belief,' Philosophical Papers 38(2), pp. 219-246, while more complex, deals with Velleman's point by clarifying the motivational differences between believing and imagining. I don't deal with the motivational differences between imagining and belief at greater length because these authors have already treated them very well.

${ }^{13}$ I thank an anonymous referee for this journal for raising this issue.

${ }^{14}$ Early functionalists who analogized the mind to a Turing machine may have had a non-normative sense of 'function' in mind. They understood mental states like mathematical functions, producing particular outputs in response to particular inputs. Unlike behaviorists, they allowed the outputs to be effects on other mental states rather than outward behavior. For a discussion of the mathematical and normative ways of understanding functionalism, see Sober, E. (1990). 'Putting the Function Back Into Functionalism,' in W. Lycan (ed.) Mind and Cognition. Oxford: Blackwell, pp. 63-70. While I (unlike Sober) am inclined towards a non-normative form of functionalism, I argue here that even those attracted to normative functionalism shouldn't require a further normative attitude to be applied to a representation for it to be a belief. 